\title{
Diagnostic performance of confocal laser endomicroscopy for optical diagnosis of gastric intestinal metaplasia: a meta- analysis
}

Xing-kang He $\mathrm{H}^{1,2}$, Dan Liü ${ }^{3}$ and Lei-min Sun ${ }^{1,2^{*}}$

\begin{abstract}
Background: Gastric intestinal metaplasia (IM) is generally considered as a precancerous condition, a related risk factor for intestinal-type gastric cancer. However, an accurate endoscopic diagnosis of IM is a clinical challenge. Confocal Laser Endomicroscopy (CLE) is a newly technique that can provide real-time magnified images and visualize tissues at cellular or subcellular levels. The aim of this study is to clarify the diagnostic value of CLE in detection of IM in patients at high risk of gastric cancer.
\end{abstract}

Methods: Systematic literature searches up to April 2015 in PubMed, Embase, Web of Science, Cochrane Library databases were conducted by two reviewers independently. The Quality Assessment of Diagnostic Accuracy Studies-2 (QUADAS-2) tool was applied to assess study quality and to reduce potential bias. A meta-analysis using Meta-Disc (version 1.4) and STATA software (version 13) was performed.

Results: A total of four studies enrolled 218 patients and 579 lesions were included in this meta-analysis. On per-lesion basis, the pooled sensitivity and specificity of CLE were $0.97(95 \%$ confidence interval $(\mathrm{Cl})=0.94-0.98)$ and 0.94 (95\% Cl=0.91-0.97) respectively. The pooled positive likelihood ratio (PLR) and negative likelihood ratio (NLR) were $15.20(95 \% \mathrm{Cl}=9.46-24.41)$ and $0.04(95 \% \mathrm{Cl}=0.02-0.07)$ respectively. The pooled diagnostic odds ratio (DOR) was $479.59(95 \% \mathrm{Cl}=205.64-1118.51)$ and summary receiver operating curve (SROC) area under the curve was 0.9884 . There was no statistical significance of publication bias.

Conclusion: $\mathrm{CLE}$ is a promising endoscopic tool in the detection of IM with the relatively high diagnostic value in patients at high risk of gastric cancer.

Keywords: Confocal laser endomicroscopy, Intestinal metaplasia, Diagnostic performance

Abbreviations: $\mathrm{Cl}$, Confidence interval; CLE, Confocal laser endomicroscopy; DOR, Diagnostic odds ratio; FN, False negative; FP, False positive; IM, Intestinal metaplasia; NBI, Narrow-band imaging; NLR, Negative likelihood ratio; PLR, Positive likelihood ratio; QUADAS-2, Quality assessment of diagnostic accuracy studies-2; SROC, Summary receiver operating curve; TN, True negative; TP, True positive

\footnotetext{
*Correspondence: sunleimin@yahoo.com

'Department of Gastroenterology, Sir Run Run Shaw Hospital, Zhejiang

University Medical School, Hangzhou 310016, China

${ }^{2}$ Institute of Gastroenterology, Zhejiang University (IGZJU), Hangzhou 310016,

China

Full list of author information is available at the end of the article
} 


\section{Background}

Gastric cancer is an aggressive disease, which is the second leading cause of cancer-related death globally [1]. It is well acknowledged that the pathogenesis of stomach cancer is a multi-step and sequential process beginning with chronic atrophic gastritis, going through intestinal metaplasia (IM), intraepithelial neoplasia and finally developing into adenocarcinoma [2-5]. The IM is generally considered as a premalignant lesion contributing to the development of gastric tumor [6, 7]. Current diagnosis of IM is based on pathological assessment of biopsy specimens with white-light endoscopy [8]. This conventional method is time-consuming and inefficient. It fails to detect IM whose mucosal surface looks normal. Improved endoscopic techniques such as chromoendoscopy, magnifying endoscopy, narrow-band imaging (NBI) technique have been shown to improve detection and diagnosis of IM during endoscopy $[9,10]$. Above all techniques, however, are suboptimal for the detection of IM. None of them can distinguish the structure of individual cells or microstructures, and so pathologic assessment is still required $[11,12]$. Recently, a new endoscopic technique called Confocal Laser Endomicroscopy (CLE) is applied to the detection of many gastrointestinal diseases [13-16]. It combines conventional whitelight endoscopy with confocal laser microscopy and can be divided into two types:endoscope-based CLE (e-CLE) and probe-based CLE (p-CLE) [17]. The greatest advantage of CLE is to simultaneously provide macroscopic and microscopic images of the gastrointestinal epithelium [18]. The CLE has been reported to reveal high diagnostic value for digestive diseases [13, 14, 19, 20]. However, a comprehensive systematic review of the diagnostic performance of CLE on IM has not been reported.

In this meta-analysis, the goal is to establish diagnostic accuracy of CLE in diagnosis of IM in the high-risk group of gastric cancer.

\section{Methods}

\section{Search strategy}

A systematical search was conducted on PubMed, Web of Science, Embase, Cochrane Library databases to collect relevant articles published before April 2015. The search terms were: ("confocal endoscopy" OR "confocal laser endomicroscopy" OR “CLE”) AND ("IM" OR “intestinal metaplasia"). To avoid missing studies, we also examined the reference lists of all related articles for any additional papers. Two authors extracted the data from these articles independently. Authors of these articles were contacted by email if further detailed information are needed.

\section{Selection criteria}

Articles were included in studies if they met all the following criteria: (1) using CLE to evaluate diagnostic accuracy of IM; (2) containing available data for constructing contingency tables for true positive (TP), false positive (FP), false negative (FN) and true negative (TN); (3) applying histopathology as a reference standard. Articles that met any one of the following criteria were excluded: (1) Insufficient data to construct contingency tables; (2) No histological diagnosis of lesions; (3) Reviews, case reports, abstracts and editorials.

\section{Data extraction and quality assessment}

$\mathrm{TP}, \mathrm{FP}, \mathrm{FN}$ and TN from original studies were independently extracted to construct $2 \times 2$ tables by two reviewers. First author, publication year, country, number of patients, number of lesions, patients' ages, sex ratio, histological diagnosis, number of endoscopists and endoscopes used from each studies were also extracted from studies. Discrepancies were resolved by discussions. The Quality Assessment of Diagnostic Accuracy Studies-2 (QUADAS-2) [21] was applied to assess study quality and potential bias. The QUADAS-2 tool contains four key domains that are rated in terms of the risk of bias. Quality assessment of the included studies was performed by two reviewers independently.

\section{Statistical methods}

Data were analyzed by Meta-Disc (version 1.4) and STATA software (version 13). The pooled sensitivity, specificity, PLR, NLR and DOR were estimated by a fixed-effect model (Mantel-Haenszel method). Heterogeneity across the studies was tested by the Cochrane $\mathrm{Q}$ test. Inconsistency $\left(\mathrm{I}^{2}\right)$ was used to express the percentage variability attributable to heterogeneity. $\mathrm{I}^{2}$ larger than $50 \%$ indicates heterogeneity is statistically significant, and P-values less than 0.1 illustrates the presence of heterogeneity among studies. The SROC and the area under the curve (AUC) were also constructed to illustrate the diagnostic precision of CLE. Finally, a funnel plot was constructed by Deeks' asymmetry test to evaluate publication bias of selected studies.

\section{Results}

\section{Included studies}

Four eligible studies were selected from the literature after searching the databases [22-25]. Fig. 1 shows how studies were screened from the literature. Overall 218 patients were enrolled in final analysis, with average of 54.5 patients per study (range from 20 to 85 patients). Information of per-lesion but not per-patient analyses was provided by all included studies. The CLE and white-light endoscopy were used to diagnose IM in all of included studies plus virtual chromoendoscopy was also performed in one study [24]. Additionally, virtual chromoendoscopy magnifying flexible spectral imaging color enhancement (ME-FICE) and p-CLE were applied to 


\section{Potential relevant studies identified and screened for retrieval \\ PubMed $(\mathrm{N}=57)$ \\ Web of science $(\mathrm{N}=165)$ \\ Embase( $\mathrm{N}=51)$ \\ Cochrane library $(\mathrm{N}=6)$}

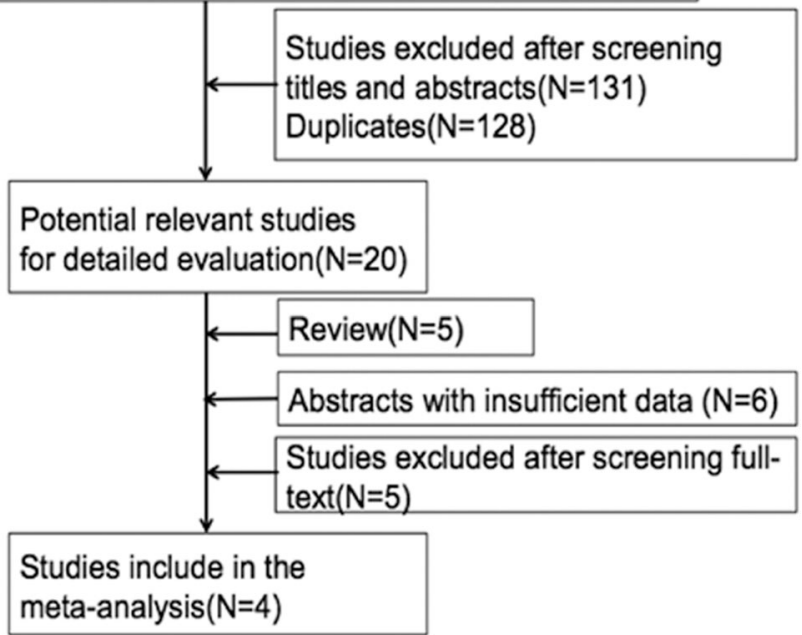

Fig. 1 Literature search flow diagram

detect GIM in another study [20]. The main findings of the studies were presented in Table 1.

\section{Study characteristics and quality assessment}

According to the QUADAS-2 criteria, the quality of the inclueded studies was shown in Table 2. Generally, most of included studies met the quality criteria.

\section{Diagnostic performance of CLE}

Based on the data from the four studies enrolling 218 participants and 579 lesions, the pooled sensitivity and specificity of CLE on per-lesion level were 0.97 (95 \% CI $=0.94-0.98)$ and $0.94(95 \% \mathrm{CI}=0.91-0.97)$ respectively (Figs. 2a and b). The pooled PLR was 15.20 (95\% CI = 9.46-24.41), and the pooled NLR was 0.04 (95\% CI = 0.02-0.07) (Figs. 3a and b). The AUC and pooled DOR were 0.9884 and 479.59 (95 \% CI $=205.64-1118.51)$ respectively (Figs. 4 and 5), indicating a high performance of diagnostic accuracy for CLE in detection of IM among the high-risk group of gastric cancer. The Cochran's Q and $\mathrm{I}^{2}$ for DOR were $2.23(\mathrm{p}=0.527)$ and 0 , respectively, demonstrating low heterogeneity among the four studies for a per-lesion analysis. Deeks' funnel plot which was not significantly asymmetrical (Fig. 6) illustrated no significant publication bias in this meta-analysis.

\section{Discussion}

Gastric cancer is still one of the most prevalent and lethal malignant diseases worldwide despite a decrease in its incidence recent decades. Early diagnosis of gastric cancer plays an important role in patients' prognoses. Gastric intestinal metaplasia (IM) is a relatively

Table 1 Characteristics of the selected studies

\begin{tabular}{|c|c|c|c|c|c|c|c|c|}
\hline$\overline{\text { Study(Year) }}$ & Country & $\begin{array}{l}\text { Numbers of } \\
\text { patients,n }\end{array}$ & $\begin{array}{l}\text { Lesions } \\
\text { examined, } \mathrm{n}\end{array}$ & $\begin{array}{l}\text { Mean } \\
\text { age,year }\end{array}$ & $\begin{array}{l}\mathrm{M} / \\
\mathrm{F}^{*}\end{array}$ & $\begin{array}{l}\text { Histological reference } \\
\text { standard }\end{array}$ & $\begin{array}{l}\text { Endoscopists } \\
\text { Number,n }\end{array}$ & $\begin{array}{l}\text { Type of CLE } \\
\text { system }\end{array}$ \\
\hline $\begin{array}{l}\text { Guo etal [27] } \\
\text { (2008) }\end{array}$ & China & 53 & 267 & 51 & $\begin{array}{l}38 / \\
15\end{array}$ & $I \mathrm{M}^{* *}$ & 3 & e-CLE \\
\hline $\begin{array}{l}\text { Zhen etal [29] } \\
\text { (2013) }\end{array}$ & China & 85 & 67 & 55 & $\begin{array}{l}45 / \\
40\end{array}$ & IM & 3 & $\mathrm{e}-\mathrm{CLE}$ \\
\hline $\begin{array}{l}\text { Rapat etal[20] } \\
(2013)\end{array}$ & Thai land & 60 & 120 & 62.8 & $\begin{array}{l}33 / \\
27\end{array}$ & IM & 5 & P-CLE \\
\hline $\begin{array}{l}\text { Lim etal [19] } \\
\text { (2013) }\end{array}$ & Singapore & 20 & 125 & 62.5 & $15 / 5$ & IM & 1 & P-CLE \\
\hline
\end{tabular}


Table 2 Quality of articles using the QUADAS tool

\begin{tabular}{|c|c|c|c|c|c|c|c|}
\hline \multirow[t]{2}{*}{ Study } & \multicolumn{3}{|l|}{ Risk of bias } & \multicolumn{4}{|c|}{ Applicability Concerns } \\
\hline & Patient selection & Index test & Reference standard & Flow and timing & Patient selection & Index test & Reference standard \\
\hline Guo etal [27] (2008) & $\mathrm{L}$ & L & L & $\mathrm{L}$ & L & $\mathrm{L}$ & L \\
\hline Zhen etal [29] (2014) & $\mathrm{L}$ & L & L & L & L & L & $L$ \\
\hline Rapat etal [20] (2013) & $\mathrm{H}$ & $L$ & L & L & $\mathrm{H}$ & L & $L$ \\
\hline Lim etal [19] (2013) & $\mathrm{L}$ & $\mathrm{L}$ & L & $\mathrm{L}$ & L & $\mathrm{L}$ & $\mathrm{L}$ \\
\hline
\end{tabular}

$L$ low risk; $H$ high risk; $U$ nuclear risk

frequent precancerous lesion and the progression rate from IM to gastric cancer over 5 years varies from 1.25 to $42 \%[19,20]$. Correa et al. reported that incomplete-type IM should be followed by surveillance in order to early diagnosis of dysplasia or early adenocarcinoma [26]. In this context, it may be justified to monitor IM in some patients (such as positive $\mathrm{H}$. pylori infection) at high risk of gastric cancer in order to early detection [26, 27]. However, conventional WLE with multiple random biopsies was unable to detect IM effectively because of the significant sampling error $[22,28]$. The CLE is a novel endoscopic technique for detection of the gastrointestinal mucosa in vivo with the help of WLE by a microscopy. The new device is integrated into the distal site of the conventional endoscope and can also perform targeted biopsy and virtual histological diagnosis with the help of WLE. Although e-CLE is reported to have a better diagnosis of Barrett's esophagus and tumors compared with pCLE [29-31], p-CLE has gained more popularity in detection of various gastrointestinal diseases recently
[32]. The p-CLE has a slightly lower resolution and smaller field of view, nevertheless, it is more practical because of greater versatility of its probes and faster frame rate to acquire images [32]. Since microscopic visualization of the gastrointestinal structures could be provided by CLE, the diagnostic criteria of CLE on IM corresponds well with histopathologic criteria. All studies adopted the similar diagnostic criteria proposed by Guo et al. in 2008 [22]. The IM can be identified in CLE if any one of the following features is present in the image field: goblet cells, villiform shape of foveolar epithelium and columnar absorptive cells.

To our knowledge, our meta-analysis was first to summarize the available evidence currently with respect to the diagnostic value of CLE in characterizing of IM. Due to insufficient data, it was impossible to estimate diagnostic value of CLE on a per-patient basis. As mentioned earlier, the summary sensitivity and specificity of CLE were 0.97 (95 \% CI $=0.94-$ $0.98)$ and $0.94(95 \% \mathrm{CI}=0.91-0.97)$ respectively. The pooled DOR was 479.59 (95\% CI $=205.64-1118.51)$.

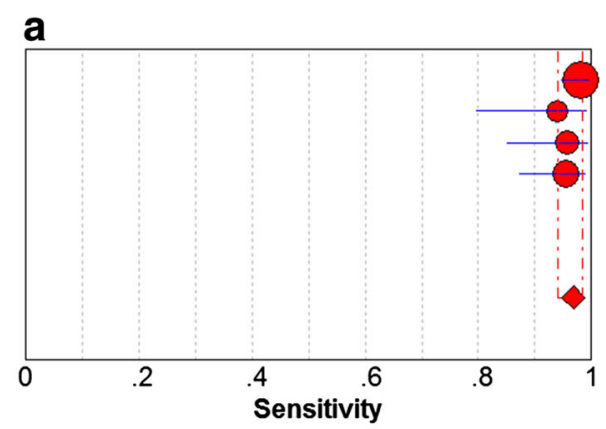

Guo et al 2008

Li et al 2014

Lim et al 2013

Sensitivity $(95 \% \mathrm{Cl})$

$0.98 \quad(0.95-1.00)$

$0.94 \quad(0.80-0.99)$

$0.96 \quad(0.85-0.99)$

$0.95 \quad(0.87-0.99)$

Pooled Sensitivity $=0.97$ (0.94 to 0.98$)$

Chi-square = 2.27; $\mathrm{df}=3(\mathrm{p}=0.5185)$

Inconsistency (I-square) $=0.0 \%$

b

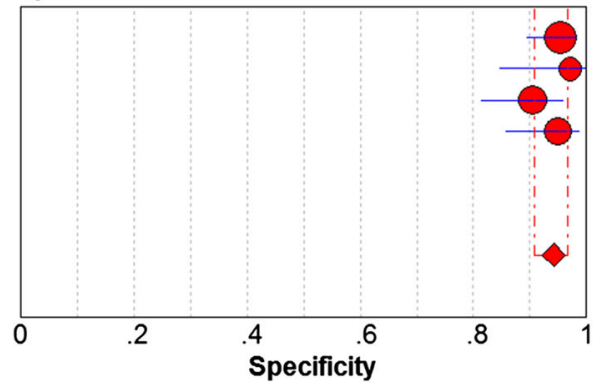

Guo et al 2008

Li et al 2014

Pittayanon et al 2013

Lim et al 2013

\section{Specificity (95\% Cl) \\ $0.95 \quad(0.89-0.98)$ \\ $0.97 \quad(0.85-1.00)$ \\ $0.91 \quad(0.81-0.96)$ \\ $0.95 \quad(0.86-0.99)$}

Pooled Specificity $=0.94$ (0.91 to 0.97 )

Chi-square $=2.48 ; \mathrm{df}=3(\mathrm{p}=0.4796)$

Inconsistency (I-square) $=0.0 \%$

Fig. 2 Forest plot showing pooled sensitivity and specificity for CLE to diagnose IM. a forest plots of the sensitivity; $\mathbf{b}$ forest plots of the specificity 


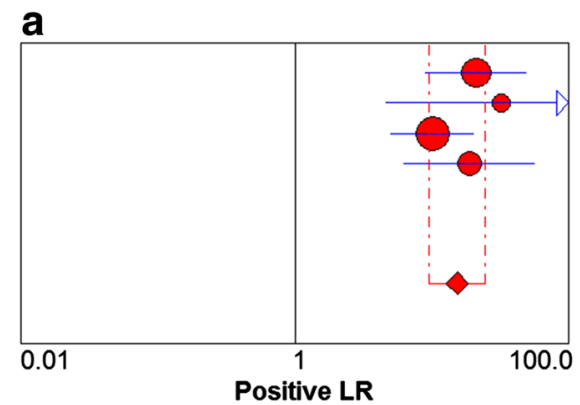

b

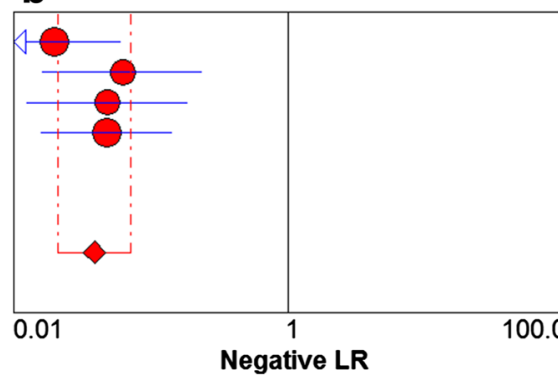

Guo et al 2008

Li et al 2014

Pittayanon et al 2013

Lim et al 2013

Random Effects Mode

Pooled Positive LR = 15.20 (9.46 to 24.41)

Cochran- $\mathrm{Q}=2.86 ; \mathrm{df}=3(\mathrm{p}=0.4133)$

Inconsistency (I-square) $=0.0 \%$

Tau-squared $=0.0000$

\section{Positive LR (95\% Cl) \\ $21.00 \quad(8.92-49.43)$ \\ $31.94 \quad(4.62-220.68)$ \\ $10.11 \quad(4.98-20.52)$ \\ $18.77 \quad(6.23-56.61)$}

Guo et al 2008

Li et al 2014

Pittayanon et al 2013

Lim et al 2013

Random Effects Model

Pooled Negative LR $=0.04$ (0.02 to 0.07)

Cochran- $Q=2.16 ; \mathrm{df}=3(\mathrm{p}=0.5397)$

Inconsistency (I-square) $=0.0 \%$

Tau-squared $=0.0000$

Fig. 3 Forest plot showing positive $L R$ and negative $L R$ of $C L E$ for $I M$. a forest plots of the positive $L R$; $\mathbf{b}$ forest plots of the negative $L R$. $L R$, likelihood ratio

These statistical results indicated that CLE had a high level of diagnostic accuracy for IM with the help of WLE. Compared with NBI, which was considered as an extremely useful diagnostic tool for IM [33], CLE had higher sensitivity (96.7\% VS $69 \%$ ), similar specificity (94. \% VS $91 \%$ ) and similar AUC (99\% VS $90 \%$ ) on a per-

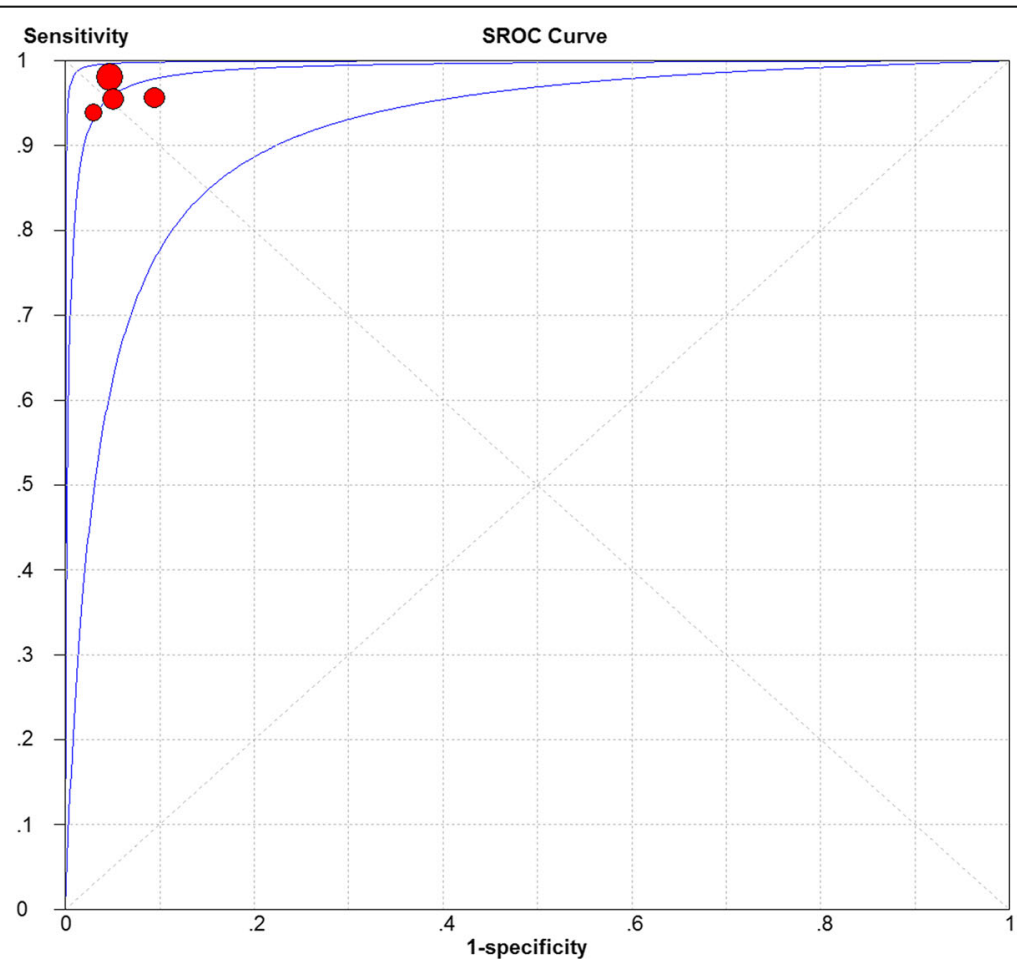

Fig. 4 SROC curve of CLE for IM. SROC, summary receiver operating characteristic, AUC: Area under curve; SE: Standard error 


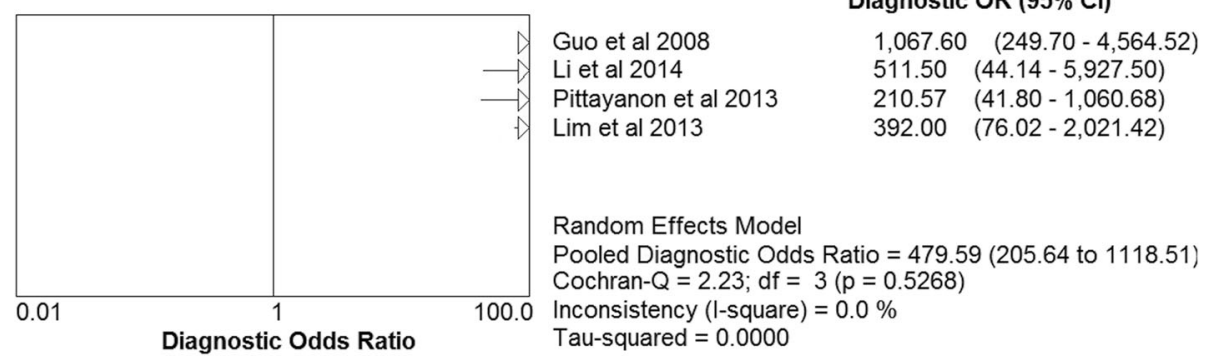

Fig. 5 Forest diagnostic odds ratio of CLE for IM

lesion basis [33]. Besides, biopsy examinations required complex and time-consuming procedures. It should be noted that the CLE may not be cost effective compared with the conventional tool [23]. Targeted biopsy by $\mathrm{p}$-CLE was more efficient as less numbers of biopsies are required compared with conventional biopsies. Zhen [23] reported that numbers of biopsies per patient by CLE targeting of biopsies could decrease $68 \%$ compared with standard biopsy protocol. We also searched studies in order to evaluate the diagnostic accuracy of CLE for intraepithelial neoplasia (IN) in this study. Unfortunately, there were few studies. Li [34] reported that CLE had a higher sensitivity (88.9\%), specificity $(99.3 \%)$ and accuracy $(98.8 \%)$ for identification of gastric cancer or HGIN lesions than WLE diagnosis alone. These data also favored to support that CLE was a promising tool in characterizing of precancerous lesions and early gastric cancer in vivo.
Several precautions should also be considered in this study. First of all, the four studies included in this metaanalysis all came from Asia. There were no similar researches in other regions so far. So researches with high quality data across multiple centers were imperative to evaluate the effectiveness of CLE to diagnose IM. Secondly, not all data could be extracted from the abstracts of studies, another factor of eliminating some studies. At last, only studies published in English were included. The selections might lead to an existing language bias and missing some useful information.

\section{Conclusion}

In summary, CLE is a reliable technique to diagnose IM with high accuracy according to our study. CLE could be considered as a promising endoscopic tool to characterize IM in patients with high risk of gastric cancer.

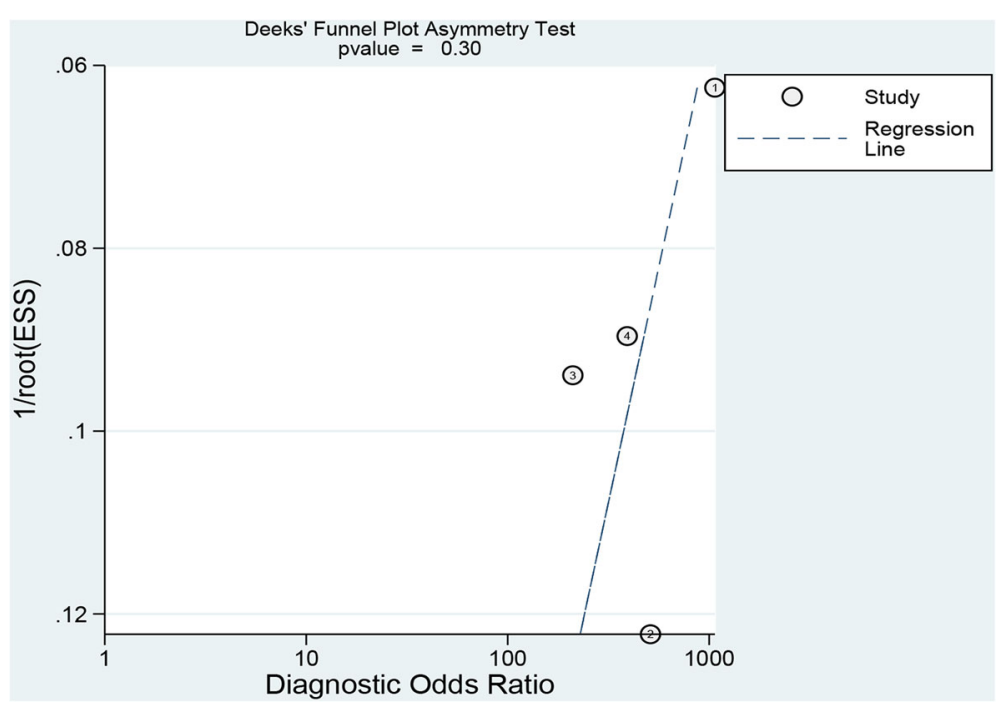

Fig. 6 Deeks' funnel plot to assess publication bias of selected studies 


\section{Acknowledgement}

The authors thank Ms. Dong Wenjie, Dr. Wei Wang, Jane Sadowsky for their revisions of our manuscript.

\section{Funding}

The work was funded by the Zhejiang provincial medical platform 2015 specialists class B (2015 RCB016); Zhejiang province key science and technology innovation team (2013TD13).

\section{Availability of data and materials}

The raw data supporting our findings is public and can be retrieved from Medline database.

\section{Authors' contributions}

SLM and HXK contributed to conception and design of the study. HXK and LD contributed to the data acquisition, analysis and interpretation of the data. HXK and LD contributed to writing and editing the manuscript. All authors commented on drafts of the paper and have approved the final draft of the manuscript.

\section{Competing interests}

The authors declare that they have no competing interests.

\section{Consent for publication}

Not applicable.

\section{Ethics approval and consent to participate}

All analyses were based on previous published studies, thus no ethical approval and patient consent are required.

\section{Author details}

'Department of Gastroenterology, Sir Run Run Shaw Hospital, Zhejiang University Medical School, Hangzhou 310016, China. ${ }^{2}$ Institute of Gastroenterology, Zhejiang University (IGZJU), Hangzhou 310016, China. ${ }^{3}$ Department of Statistics, Texas A \& M University, College Station, TX 77843 , USA

Received: 1 December 2015 Accepted: 10 August 2016

Published online: 05 September 2016

\section{References}

1. Torre LA, Bray F, Siegel RL, Ferlay J, Lortet-Tieulent J, Jemal A. Global cancer statistics, 2012. CA Cancer J Clin. 2015;65(2):87-108.

2. Correa P. Human gastric carcinogenesis: a multistep and multifactorial process-First American Cancer Society Award Lecture on Cancer Epidemiology and Prevention. Cancer Res. 1992;52(24):6735-40.

3. Mathe G. Is the study of human cancer-associated factors, the best or the only model for human carcinogenesis research? I. The question of Helicobacter pylori infection as an accused human gastric carcinogen. Biomed Pharmacother. 1997;51(1):1-4.

4. Correa P. A human model of gastric carcinogenesis. Cancer Res. 1988:48(13):3554-60.

5. Zhao H, Yang $X$, Zhou Y, Zhang W, Wang Y, Wen J, Zhang Z, Shen L. Potential role of aquaporin 3 in gastric intestinal metaplasia. Oncotarget. 2015;6(36):38926-33

6. You WC, Zhang L, Gail MH, Li JY, Chang YS, Blot WJ, Zhao CL, Liu WD, Li HQ Ma JL, et al. Precancerous lesions in two counties of China with contrasting gastric cancer risk. Int J Epidemiol. 1998:27(6):945-8.

7. Busuttil RA, Zapparoli GV, Haupt S, Fennell C, Wong SQ, Pang JM, Takeno EA, Mitchell C, Di Costanzo N, Fox S, et al. Role of p53 in the progression of gastric cancer. Oncotarget. 2014;5(23):12016-26.

8. Redeen S, Petersson F, Jonsson KA, Borch K. Relationship of gastroscopic features to histological findings in gastritis and Helicobacter pylori infection in a general population sample. Endoscopy. 2003;35(11):946-50.

9. Costamagna G, Marchese M. Progress in endoscopic imaging of gastrointestinal tumors. Eur Rev Med Pharmacol Sci. 2010;14(4):272-6.

10. Gong S, Xue HB, Ge ZZ, Dai J, Li XB, Zhao YJ, Zhang Y, Gao YJ, Song Y. Value of magnifying endoscopy with narrow-band imaging and confocal laser endomicroscopy in detecting gastric cancerous lesions. Medicine (Baltimore). 2015;94(44):e1930.
11. Uedo $N$, Ishihara $R$, lishi $H$, Yamamoto $S$, Yamamoto $S$, Yamada T, Imanaka $K$, Takeuchi Y, Higashino K, Ishiguro S, et al. A new method of diagnosing gastric intestinal metaplasia: narrow-band imaging with magnifying endoscopy. Endoscopy. 2006;38(8):819-24.

12. Inoue $T$, Uedo N, Ishihara R, Kawaguchi T, Kawada N, Chatani R, Kizu T, Tamai C, Takeuchi Y, Higashino K, et al. Autofluorescence imaging videoendoscopy in the diagnosis of chronic atrophic fundal gastritis. J Gastroenterol. 2010;45(1):45-51.

13. Qumseya BJ, Wang H, Badie N, Uzomba RN, Parasa S, White DL, Wolfsen H, Sharma P, Wallace MB. Advanced imaging technologies increase detection of dysplasia and neoplasia in patients with Barrett's esophagus: a meta-analysis and systematic review. Clin Gastroenterol Hepatol. 2013;11(12):1562-70. e1561-1562.

14. Dong YY, Li YQ, Yu YB, Liu J, Li M, Luan XR. Meta-analysis of confocal laser endomicroscopy for the detection of colorectal neoplasia. Colorectal Dis. 2013;15(9):e488-95.

15. Yeung TM, Mortensen NJ. Advances in endoscopic visualization of colorectal polyps. Colorectal Dis. 2011;13(4):352-9.

16. Ypsilantis E, Pissas D, Papagrigoriadis S, Haji A. Use of confocal laser endomicroscopy to assess the adequacy of endoscopic treatment of gastrointestinal neoplasia: a systematic review and meta-analysis. Surg Laparosc Endosc Percutan Tech. 2014;25(1):1-5.

17. Neumann H, Kiesslich R, Wallace MB, Neurath MF. Confocal laser endomicroscopy: technical advances and clinical applications. Gastroenterology. 2010;139(2):388-92. e381-382.

18. Kiesslich R, Goetz M, Vieth M, Galle PR, Neurath MF. Confocal laser endomicroscopy. Gastrointest Endosc Clin N Am. 2005;15(4):715-31.

19. Wu J, Pan YM, Wang TT, Hu B. Confocal laser endomicroscopy for detection of neoplasia in Barrett's esophagus: a meta-analysis. Dis Esophagus. 2014:27(3):248-54

20. Wanders LK, East JE, Uitentuis SE, Leeflang MM, Dekker E. Diagnostic performance of narrowed spectrum endoscopy, autofluorescence imaging, and confocal laser endomicroscopy for optical diagnosis of colonic polyps: a meta-analysis. Lancet Oncol. 2013:14(13):1337-47.

21. Whiting PF, Rutjes AW, Westwood ME, Mallett S, Deeks JJ, Reitsma JB, Leeflang MM, Sterne JA, Bossuyt PM, Group Q-. QUADAS-2: a revised tool for the quality assessment of diagnostic accuracy studies. Ann Intern Med. 2011:155(8):529-36.

22. Guo YT, Li YQ, Yu T, Zhang TG, Zhang JN, Liu H, Liu FG, Xie XJ, Zhu Q, Zhao YA. Diagnosis of gastric intestinal metaplasia with confocal laser endomicroscopy in vivo: a prospective study. Endoscopy. 2008;40(7):547-53.

23. Li Z, Zuo XL, Yu T, Gu XM, Zhou CJ, Li CQ, Ji R, Li YQ. Confocal laser endomicroscopy for in vivo detection of gastric intestinal metaplasia: a randomized controlled trial. Endoscopy. 2014;46(4):282-90.

24. Lim LG, Yeoh KG, Srivastava S, Chan YH, Teh M, Ho KY. Comparison of probe-based confocal endomicroscopy with virtual chromoendoscopy and white-light endoscopy for diagnosis of gastric intestinal metaplasia. Surg Endosc. 2013;27(12):4649-55.

25. Pittayanon R, Rerknimitr R, Wisedopas N, Ridtitid W, Kongkam P Treeprasertsuk S, Angsuwatcharakon P, Mahachai V, Kullavanijaya P. Flexible spectral imaging color enhancement plus probe-based confocal laser endomicroscopy for gastric intestinal metaplasia detection. J Gastroenterol Hepatol. 2013;28(6):1004-9.

26. Correa P, Piazuelo MB, Wilson KT. Pathology of gastric intestinal metaplasia: clinical implications. Am J Gastroenterol. 2010;105(3):493-8.

27. de Vries AC, van Grieken NC, Looman CW, Casparie MK, de Vries E, Meijer GA, Kuipers EJ. Gastric cancer risk in patients with premalignant gastric lesions: a nationwide cohort study in the Netherlands. Gastroenterology. 2008;134(4):945-52

28. Sauerbruch T, Schreiber MA, Schussler P, Permanetter W. Endoscopy in the diagnosis of gastritis. Diagnostic value of endoscopic criteria in relation to histological diagnosis. Endoscopy. 1984;16(3):101-4.

29. Kiesslich R, Gossner L, Goetz M, Dahlmann A, Vieth M, Stolte M, Hoffman A, Jung M, Nafe B, Galle PR, et al. In vivo histology of Barrett's esophagus and associated neoplasia by confocal laser endomicroscopy. Clin Gastroenterol Hepatol. 2006:4(8):979-87.

30. Wallace MB, Sharma P, Lightdale C, Wolfsen H, Coron E, Buchner A, Bajbouj M, Bansal A, Rastogi A, Abrams J, et al. Preliminary accuracy and interobserver agreement for the detection of intraepithelial neoplasia in Barrett's esophagus with probe-based confocal laser endomicroscopy. Gastrointest Endosc. 2010;72(1):19-24. 
31. Bajbouj M, Vieth M, Rosch T, Miehlke S, Becker V, Anders M, Pohl H, Madisch A, Schuster T, Schmid RM, et al. Probe-based confocal laser endomicroscopy compared with standard four-quadrant biopsy for evaluation of neoplasia in Barrett's esophagus. Endoscopy. 2010:42(6):435-40.

32. Wallace MB, Fockens P. Probe-based confocal laser endomicroscopy. Gastroenterology. 2009;136(5):1509-13.

33 Song J, Zhang J, Wang J, Guo X, Wang J, Liu Y, Dong W. Meta-analysis: narrow band imaging for diagnosis of gastric intestinal metaplasia. PLoS One. 2014;9(4):e94869.

34 Li WB, Zuo XL, Li CQ, Zuo F, Gu XM, Yu T, Chu CL, Zhang TG, Li YQ. Diagnostic value of confocal laser endomicroscopy for gastric superficial cancerous lesions. Gut. 2011;60(3):299-306.

Submit your next manuscript to BioMed Central and we will help you at every step:

- We accept pre-submission inquiries

- Our selector tool helps you to find the most relevant journal

- We provide round the clock customer support

- Convenient online submission

- Thorough peer review

- Inclusion in PubMed and all major indexing services

- Maximum visibility for your research

Submit your manuscript at www.biomedcentral.com/submit
C) Biomed Central 